\title{
Endoscopic Accessories Used for More Advanced Endoluminal Therapeutic Procedures
}

\author{
Hyunsoo Chung \\ Department of Internal Medicine and Liver Research Institute, Seoul National University College of Medicine, Seoul, Korea
}

Endoscopic accessories describe an extensive variety of auxiliary instruments used for diagnostic and therapeutic endoscopy. Various endoscopic accessories have been developed over the previous few decades and are mostly used for treating neoplastic lesions, such as early gastrointestinal (GI) carcinomas and premalignant lesions. Because of extensive research on natural orifice endoluminal surgery (NOTES) in the early 2000s and recent technological developments, new devices have been developed for various advanced endoluminal therapeutic procedures. In particular, a remarkable development of endoscopic management was achieved in the field of gastroesophageal reflux disease (GERD) and obesity. In both conditions, there is treatment gap between medical and surgical therapy. A large proportion of the patients who do not respond to medical treatment and lifestyle modification, still hesitate to directly undergo surgical treatment. To bridge this gap, endoscopic management has been receiving increasing attention. In this article, I review endoscopic and/or endoluminal devices used for the treatment of GERD and obesity with proposed mechanisms of their function. Clin Endosc 2017;50:234-241

Key Words: Endoscopic accessories; Endoscopic devices; Gastroesophageal reflux; Obesity; Bariatric endoscopy

\section{INTRODUCTION}

Recent technical developments have resulted in the remarkable development of novel endoscopic devices and accessories, even though most are applied using an over-the-scope or over-the-guidewire method rather than a through-the-scope method. In particular, the use of endoscopic treatment with novel devices and methods allows for targeting of not only neoplastic lesions, but also chronic disorders, such as gastroesophageal reflux disease (GERD) and obesity. In both conditions, there is a treatment gap between medical and surgical therapy and an unmet need for less invasive treatment. To bridge this gap, endoscopic management has been the focus

Received: May 22, 2017 Accepted: May 22, 2017

Correspondence: Hyunsoo Chung

Department of Internal Medicine and Liver Research Institute, Seoul National University College of Medicine, 101 Daehak-ro, Jongno-gu, Seoul 03080, Korea Tel: +82-2-2072-4844, Fax: +82-2-743-6701, E-mail: hschungmd@gmail.com

(cc) This is an Open Access article distributed under the terms of the Creative Commons Attribution Non-Commercial License (http://creativecommons.org/ licenses/by-nc/3.0) which permits unrestricted non-commercial use, distribution, and reproduction in any medium, provided the original work is properly cited. of research.

\section{GASTROESOPHAGEAL REFLUX DISEASE}

GERD is a common disorder, affecting $20 \%$ of the adult population in the US every week. ${ }^{1}$ The prevalence of GERD has been reported to be $18.1 \%-27.8 \%$ in North America, 8.8\%-25.9\% in Europe, and $4.6 \%-10.7 \%$ in Korea. ${ }^{2-4}$ The true incidence of GERD may be higher since over-the-counter medications, such as antacids and proton pump inhibitors (PPIs), are available in many countries. Currently, medical, endoscopic, and surgical treatment are used for patients with GERD. Although PPIs have been the mainstay of medical management of GERD, there are patients who do not respond to or require chronic PPI use. The potential adverse effects of the chronic use of PPIs are also of concern. These adverse effects include enteric infections including Clostridium difficile, increased susceptibility to pneumonia, hypergastrinemia, hypomagnesemia, and higher incidence of chronic kidney disease in susceptible populations. ${ }^{5,6}$ In the late 1990s, a series of 

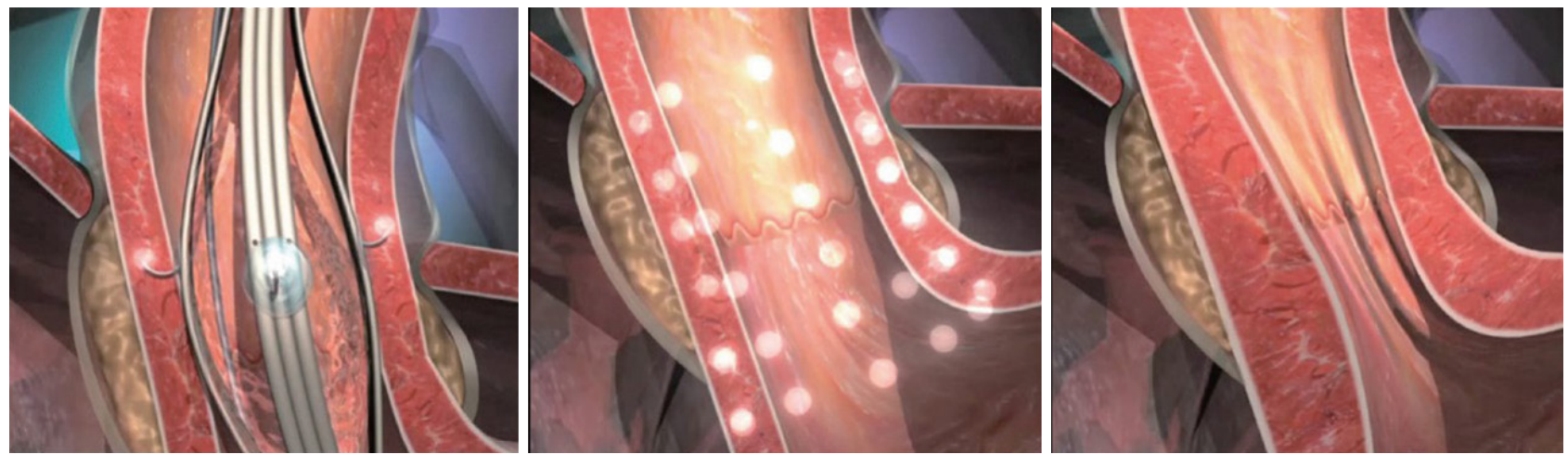

Fig. 1. Details of Stretta (Mederi Therapeutics, Greenwich, CT, United States) system (https://www.stretta-therapy.com/professionals/how-stretta-works).

endoscopic treatments for GERD were introduced, but have failed to show long-term efficacy. These treatments included implantation and injection devices (Enteryx, Gatekeeper) and tissue apposing devices (EndoCinch and NDO plicator). Nonetheless, there has been an increased interest among patients and medical professionals in minimally invasive endoscopic intervention as an alternative to surgical treatment. Endoscopic procedure can be done in out-patient basis, and is expected to avoid side effects of laparoscopic Nissen's fundoplication, such as bloating and dysphagia. ${ }^{7.8}$ Four endoscopic treatment modalities are clinically available presently: radiofrequency $(\mathrm{RF})$ treatment with the Stretta device, transoral incisionless fundoplication (TIF) with either the EsophyX device or Medigus ultrasonic surgical endostapler (MUSE), and anti-reflux mucosectomy (ARMS). In this review, I excluded MUSE which requires a novel endoscopic system and ARMS which use conventional endoscopic accessories for the procedure.

\section{Radiofrequency ablation}

The Stretta procedure, a RF application for the lower esophageal sphincter (LES), was introduced approximately 15 years ago. ${ }^{9}$ Since the initial introduction of the Stretta RF system, several minor modifications have been conducted that have facilitated the ease of use and proper application of the technique. The Stretta procedure appears to result in thickening of the LES, decreased transient LES relaxation rate, and reduced esophageal acid exposure. Possible adverse events (AEs), such as esophageal stricture or neurolysis in the distal esophagus, have not been reported over time..$^{10-12}$ The Society of American Gastrointestinal and Endoscopic Surgeons (SAGES) has indicated Stretta as an recommended therapeutic option for patients with GERD, who are over age 18 , have suffered symptoms of heartburn and/or regurgitation for at least 6 months, who have had complete or partial response to antisecretory drug medication, and who have refused surgical management. ${ }^{13}$

The Stretta system (Mederi Therapeutics, Greenwich, CT,
USA) consists of a four-channel RF generator and single-use RF energy catheters. This system delivers pure sine-wave energy ( $465 \mathrm{kHz}, 2$ to $5 \mathrm{~W}$ per channel). Each needle tip incorporates a thermocouple that automatically adjusts the power output to a desired target temperature in the muscle layer. Automatic thermoregulation maintains the temperature of the electrode below $100^{\circ} \mathrm{C}$ to minimize neighboring tissue damage due to vaporization and high impedance values. Power delivery stops if mucosal temperature exceeds $47^{\circ} \mathrm{C}$. $\mathrm{RF}$ energy is applied to four points located $1 \mathrm{~cm}$ proximal to the $\mathrm{Z}$ line first. Next, change the direction of the electrodes about $45^{\circ}$ degree, and RF energy is applied to four more points at the same level delivering RF energy to a total of eight points at the same level. This procedure is repeated at three more levels at intervals of $0.5 \mathrm{~cm}$ (Fig. 1). ${ }^{14}$ The potential action mechanism of RF delivery appears to be related with smooth muscle hypertrophy at the cellular level in an animal model which includes redistribution of the interstitial cells of Cajal and a change in the muscle fiber to connective tissue ratio (increase in collagen 1 and decrease in collagen $3 .{ }^{15}$

\section{Transoral incisionless fundoplication}

The TIF is a minimally invasive therapeutic procedure for GERD that is done transorally from the inside of patient's stomach without incisions. This procedure delivers patient outcomes similar to those of conventional anti-reflux surgery (ARS) procedures, but is less invasive. The TIF procedure reconstructs the gastroesophageal valve through a partial fundoplication and helps to restore the dynamics of the angle of His as the anti-reflux barrier. EsophyX device (EndoGastric Solutions, Inc., Redmond, WA, USA) is consisted with is consisted with: (1) a handle; (2) an 18-mm diameter frame that includes operative channels through which a frontview 9-mm diameter endoscope can be inserted; (3) the invaginator, provided by side holes on the distal part of the chassis, to which external suction can be applied; (4) the tissue mold, which can be brought into retroflection and pushes tissue against the 


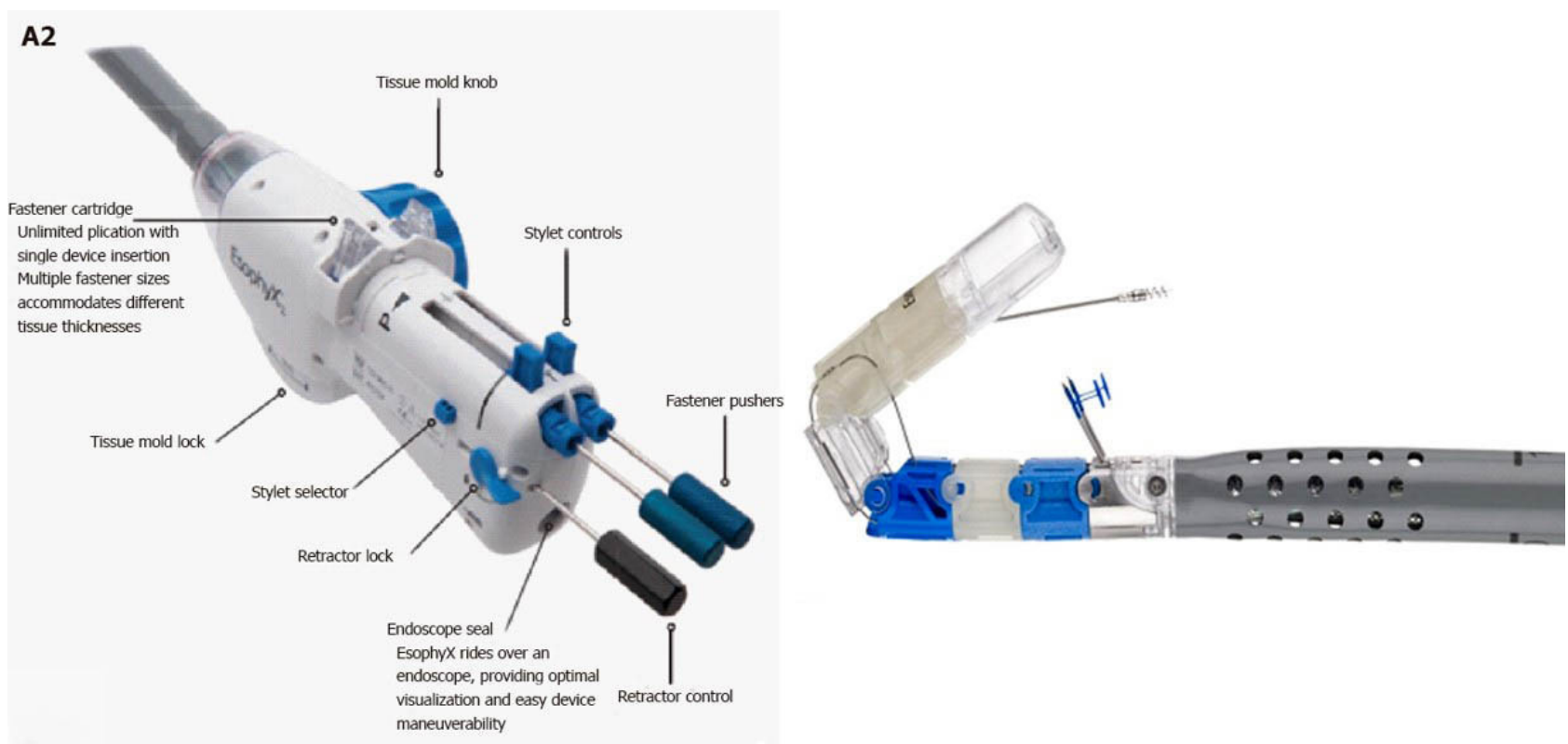

Fig. 2. Details of the EsophyX (EndoGastric Solutions, Inc., Redmond, WA, United States) device (http://www.endogastricsolutions.com/technology/esophyx-device/).

shaft of the device; (5) a helical retractor, which is advanced into the tissue so the tissue between the tissue mold and the shaft can be retracted; (6) two stylets, which pass through the plicated tissue and the tissue mold, and $\mathrm{H}$-shaped polypropylene fasteners which maintain tissue compression throughout healing process can be deployed over them; and (7) a cartridge containing 20 fasteners. Recently updated instrument, the EsophyX Z device has fastener deployment to reduce control complexity. Under the direct visualization of the endoscope, the device is positioned within the LES muscle and sturdy anti-reflux valve can be created. The procedure is performed under general anesthesia (Fig. 2). ${ }^{16}$

\section{OBESITY}

Obesity represents a major health issue around the world. This multifactorial chronic disease has a growing prevalence and has reached epidemic proportions over the previous few decades. ${ }^{17}$ According to recent survey results, more than half (53.8\%) of the adult population in Organization for Economic Cooperation and Development (OECD) countries are overweight or obese. Although the overweight and obesity rates are much lower in Japan and Korea, the rates even in these countries are increasing. The prevalence of obesity, which presents even greater health risks than being overweight, varies approximately six-fold across OECD countries, from a low of 5\% in Japan and Korea, to over 32\% in Mexico and the United States. ${ }^{18}$ Obesity is known to be associated with various medical and psychological comorbidities, increases cardiovas- cular and all-cause mortality. Although dietary and lifestyle modification are the mainstay of obesity management, it is a huge challenge for the majority of patients to permanently maintain their eating behaviors. Sustained weight loss after lifestyle modification and pharmacotherapy is achieved in less than $5 \%$ of cases. ${ }^{19,20}$ Bariatric surgery is more effective and durable in inducing weight loss and decreasing obesity-related morbidities and mortality. However, early and late complications remain as high as $30 \%$, and less than $1 \%$ of eligible patients undergo surgery. ${ }^{21}$ Consequently, there has been a need for alternative weight loss therapies that are less invasive and less risky than bariatric surgery and more effective and durable than lifestyle interventions. Recently, endoscopic bariatric therapy (EBT) has been developed to fill the gap between medical and surgical therapy. Two main endoscopic weight loss modalities are restrictive and malabsorptive..$^{22}$ The main objective of restrictive procedures is to reduce the stomach volume by space-occupying devices and/or by suturing or stapling techniques that change gastric anatomy while malabsorptive procedures tend to prevent food contact with the duodenum and proximal jejunum. Additionally, EBTs can mimic some of the anatomic alterations created by bariatric surgery by selectively targeting the stomach or the small intestines. ${ }^{23}$ In this review, endoluminal devices are separately described by their target organ: gastric and small-bowel endoscopic devices.

\section{Gastric intervention and devices}

\section{OverStitch for endoscopic sleeve gastroplasty}

The Apollo OverStitch (Apollo Endosurgery, Austin, TX, 
USA) is an endoscopic suturing device that applies full-thickness sutures in a variety of patterns. This device attaches proximally and distally to a dual channel flexible endoscope allowing for endoluminal suturing in multiple applications. The handle of device, mounted to the endoscope control handle, actuates the needle driver attached at the distal end. An anchor exchange catheter is placed in one scope channel to manage the passing of the suture, while the secondary channel can be utilized to operate the tissue helix for atraumatic tissue manipulation. Once the suturing pattern is completed, a cinching tool is deployed to provide knotless fixation. This suturing device enable running and interrupted stitches. In 2012, Thompson and Hawes reported the first human case of endoscopic sleeve gastrectomy (ESG). ${ }^{24}$ Possible mechanisms of action of EGS are decreased ghrelin without significant changes in peptide tyrosine tyrosine (PYY) or glucagon-like peptide 1 (GLP-1) levels, delayed gastric emptying and increased satiation, similar with laparoscopic sleeve gastro- plasty. ${ }^{25}$ This procedure was later modified to include medial interrupted reinforcing sutures based on the work of Abu Dayyeh et al., which reported a series of 4 patients who underwent a version of ESG using 2 rows of interrupted stitches. ${ }^{26}$ Sharaiha et al. performed ESG on 10 patients. ${ }^{27}$ Mean excess weight loss (EWL) were $18 \%$ after 1 month, $26 \%$ after 3 months, and 30\% after 6 months. ${ }^{27}$ Subsequently, other investigators have reported similar results. ${ }^{28,29}$ Recently another multicenter trial reported $48.2 \% \pm 9.9 \%$ of EWL at 12 months in 20 patients without serious AEs. ${ }^{30}$

\section{Intragastric balloon}

So far, 3 intragastric balloons (IGBs) were approved by the Food and Drug Administration (FDA) for the management of obesity. The Orbera IGB (Apollo Endosurgery, Austin, TX, USA), the ReShape Duo (ReShape Medical, San Clemente, CA, USA); and the Obalon IGB (Obalon Therapeutics Inc., Carlsbad, CA, USA). All 3 are approved to be used for
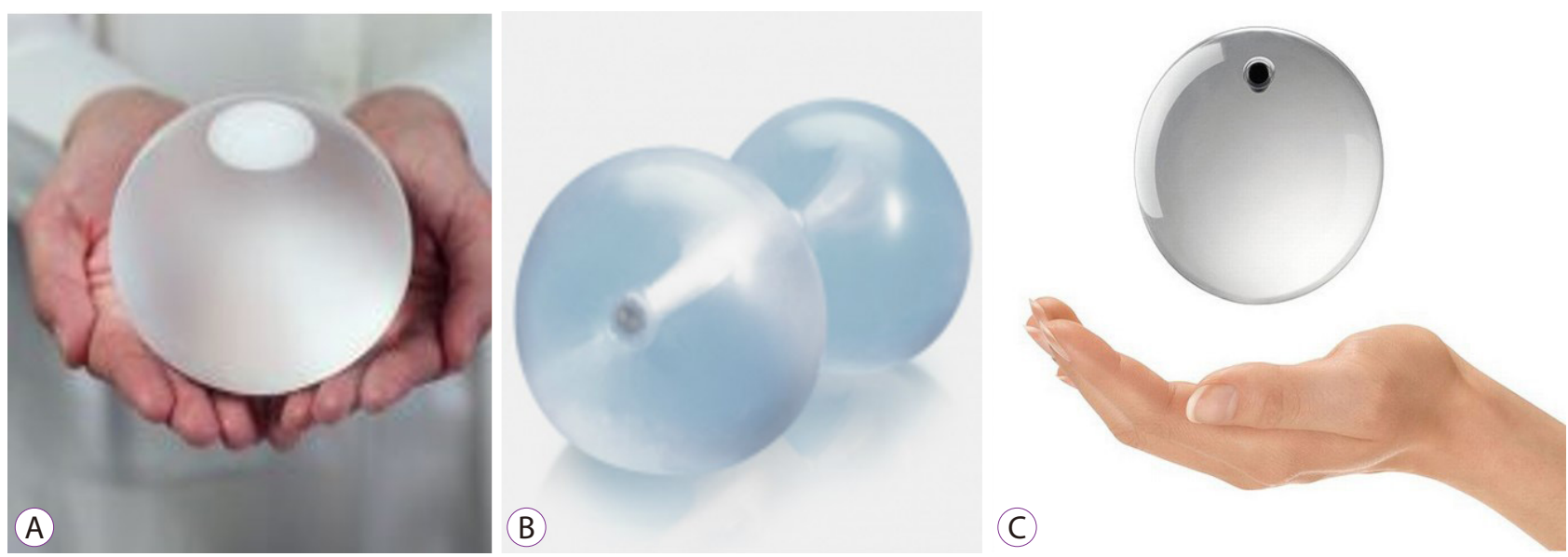

Fig. 3. Various intragastric balloons. (A) Orbera (Apollo Endosurgery, Austin, TX, United States) (https://www.orbera.com/for-hcp). (B) Reshape Duo (ReShape Medical, San Clemente, CA, United States) (http://pro.reshapeready.com/). (C) Obalon (Obalon Therapeutics, Carlsbad, CA, United States) (http://www.obalon.com/).

Table 1. Characteristics of FDA-Approved Intragastric Balloons

\begin{tabular}{lcccl}
\hline Type of IGB & $\begin{array}{c}\text { Filing } \\
\text { material }\end{array}$ & $\begin{array}{c}\text { Number of } \\
\text { balloon }\end{array}$ & Volume $(\mathbf{m L})$ & Placement and removal \\
\hline Obera & Saline & 1 & $500-750$ & $\begin{array}{l}\text { Placement: endoscopy } \\
\text { Deflation: endoscopy } \\
\text { Removal: endoscopy }\end{array}$ \\
ReShape Duo & Saline & 2 & 400 for each & $\begin{array}{l}\text { Placement: endoscopy } \\
\text { Deflation: endoscopy } \\
\text { Removal: endoscopy }\end{array}$ \\
Obalon & Gas & Up to 3 & 250 for each, up to 3 balloons & $\begin{array}{l}\text { Placement: No need of endoscopy (capsule } \\
\text { swallowing), fluoroscopy before inflation } \\
\text { Deflation: endoscopy } \\
\text { Removal: endoscopy }\end{array}$ \\
\hline
\end{tabular}

FDA, Food and Drug Administration; IGB, intragastric balloon. 
6 months (Fig. 3, Table 1). It is assumed that IGB facilitate weight loss by reducing the stomach's potential volume and inducing early satiety. In this way, total caloric intake for the day may be reduced. Action mechanism of IGB is not fully understood yet. Additional proposed mechanisms include changes in gastric emptying and hormonal changes. Gomez et al. reported that gastric emptying in subjects with IGB is delayed but returns to normal after IGB removal and greater changes in increased gastric retention were associated with greater percentage of total body weight loss (\%TBWL). ${ }^{31}$ Other proposed mechanisms include changes in hormones. Mion et al. reported that gastric emptying rates and plasma ghrelin levels were decreased in the presence of IGB and weight loss induced by the IGB was related to ghrelin variations, but not to gastric emptying. ${ }^{32}$ Ghrelin inhibition may explain part of the effect of the balloon on satiety. ${ }^{32}$ However, there are conflicting reports of observed hormonal changes in other studies and therefore, the mechanism of action appears to be multifactorial. The most common AEs include nausea, vomiting, and decreased oral intake. Many of these symptoms can be managed conservatively without the need for early balloon removal. In a large retrospective study of 2,515 patients with IGB, overall complication rate was $70 / 2,515$ (2.8\%) with 5 perforations, 4 of whom had undergone previous gastric surgery, and 2 deaths, 32 esophagitis and 5 gastric ulcers. ${ }^{33} \mathrm{~A}$ randomized, controlled trial observed only minor $\mathrm{AE}$ including belching and heartburn without any serious AEs. ${ }^{34}$

\section{Transpyloric shuttle}

Transpyloric shuttle (TPS; BAROnova, Goleta, CA, USA) is a nonsurgical device that is endoscopically delivered to and removed from the stomach. The device consists of a large

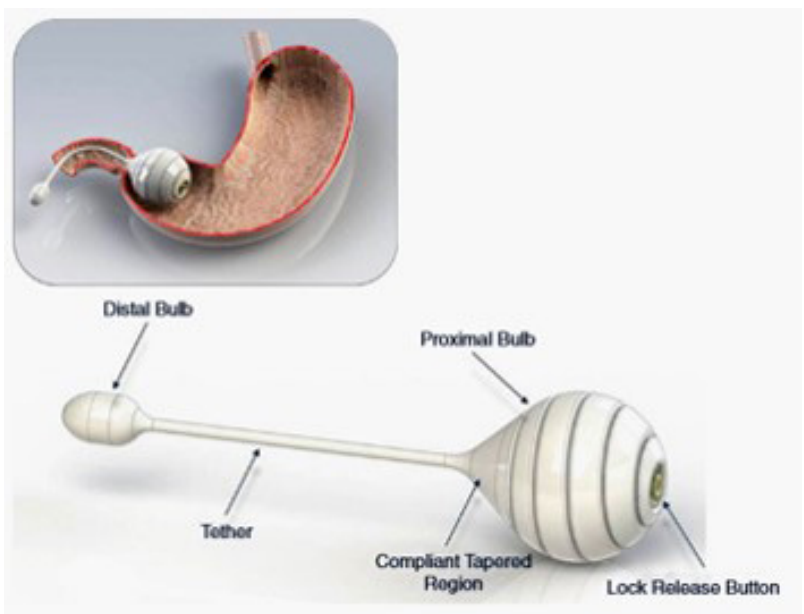

Fig. 4. Transpyloric shuttle (BAROnova, Goleta, CA, United States) (https:/l baronova.com/). spherical bulb connected to a smaller cylindrical bulb by a flexible tether (Fig. 4). The larger bulb is designed to prevent migration from the stomach, while the smaller bulb passes freely into the duodenum to position the TPS across the pylorus. Transpyloric positioning may delay gastric emptying, reducing caloric intake and enabling weight loss. The TPS appears to have several mechanisms of action that promote weight loss. The large bulb, although the size is not as large as the IGBs, may partially reduce functional gastric volume. During antral contractions, the large bulb repeatedly engages the pylorus, causing intermittent obstruction. This action delays gastric emptying, prolongs gastric accommodation, and increases satiety. It is possible that the distal bulb is interacting with duodenal mucosa and incretin signaling, although this remains to be elucidated. ${ }^{35}$ The TPS device is designed for temporary placement and does not fundamentally alter the gastrointestinal (GI) anatomy. One clinical study reported percentage of EWL (\%EWL) of $25.1 \%$, and percentage of total weight loss (\%TWL) of $8.9 \%$ in 3 months and \%EWL of $41.0 \%, \% \mathrm{TWL}$ of $14.5 \%$ in 6 month without complications. ${ }^{36}$ A 12 months multi-center prospective study (ENDObesity II Study) completed enrollment of 270 patients in 9 sites in the United States in December of 2016.

\section{Small intestinal intervention and devices}

The proximal small bowel plays an important role in glucose homeostasis. Also known as the incretin effect, oral glucose intake leads to amplification of insulin secretion compared with intravenous infusion. This effect is understood to be owing to gut hormones, such as incretins, peptide YY and oxyntomodulin. ${ }^{37-39}$ In addition to their effect on glucose homeostasis, these gut hormones also affect satiety and GI motility. Therefore, small-bowel interventions may contribute to weight loss as well as diabetes improvement. ${ }^{40}$

\section{Duodenal jejunal bypass sleeve}

Duodenal-jejunal bypass sleeve (DJBS; GI Dynamics, Lexington, MA, USA) is a reversible procedure developed to treat obesity and type 2 diabetes (Fig. 5). ${ }^{41}$ DJBS consists of a metallic anchor (Nitinol) that attaches the implant to the duodenum bulb and a $60 \mathrm{~cm}$ long GI liner that extends from duodenum to the proximal jejunum. It essentially mimics the intestinal bypass part of the Roux-en-Y surgery. DJBS with flow restrictor is a modification of DJBS which includes a $4 \mathrm{~mm}$ restrictor orifice distal to the anchor to slow gastric emptying in addition to the DJBS-mediated effects. Devices are temporary implants and can be removed after predetermined time interval. ${ }^{42}$ The DJBS implantation procedure is performed using an endoscope and fluoroscopy. ${ }^{43-48}$ The efficacy and safety, investigated by several studies showed $\% \mathrm{EWL}$ of $30 \%-47 \%$ at 52 weeks. ${ }^{49,50}$ 

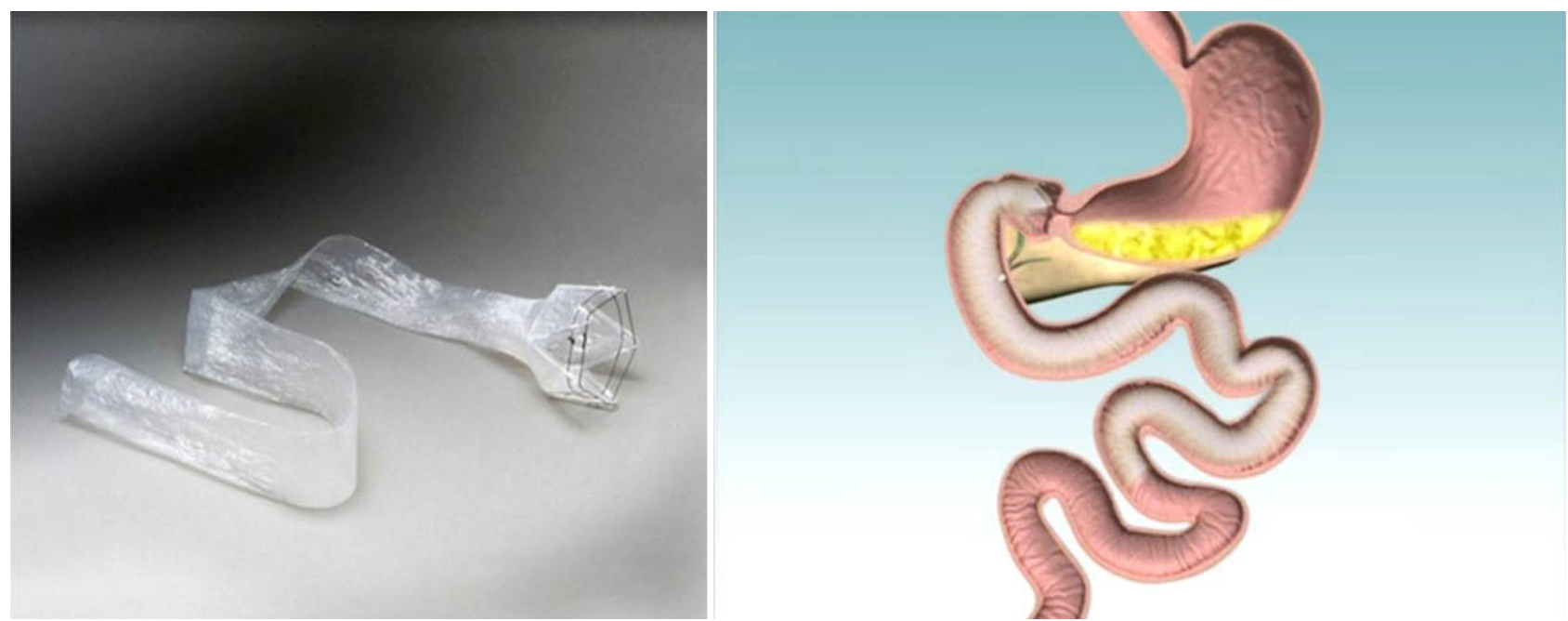

Fig. 5. Duodenal jejunal bypass sleeve (GI Dynamics, Lexington, MA, United States) (http://www.endobarrier.com/).

This device also appears to have efficacy in improving glycemic control, insulin resistance, and lipid profile. ${ }^{42}$ However, a recent meta-analysis reported that an average of $0.9 \%$ change in HbAlc was observed and failed to show statistical significance. ${ }^{46}$ Therefore, more researches are necessary to find out if DJBS can be an alternative therapy for management of type 2 diabetes and morbid obesity.

\section{Duodenal mucosal resurfacing}

The Revita duodenal mucosal resurfacing (DMR) procedure (Fractyl Laboratories Inc., Cambridge, MA, USA) involves the use of RF ablation following saline lift to induce mucosal remodeling. This may result in changes in enteroendocrine cells improving diabetic control. ${ }^{51}$ The result of a single center, single-arm, open-label, nonrandomized study of DMR in type 2 diabetes to evaluate six-month safety and efficacy has recently been published. ${ }^{52} \mathrm{HbAlc}$ was reduced by $1.2 \%$ at 6 months and longer segment ablation showed more reduction of HbAlc of $2.5 \%$, compared to $0.7 \%$ in short segment ablation group at 6 months. In 3 patients, duodenal stenosis occurred and treated successfully by balloon dilation. Long-term safety, efficacy, and durability and possible mechanisms of action require further investigation.

\section{CONCLUSIONS}

Thanks to the recent development of novel endoluminal devices, there have been remarkable progress in endoscopic management in GERD and obesity, although PPIs in GERD and surgery in Obesity remain the mainstay of the treatment. Endoscopic management may bridge the gap between medication and surgery. In addition, because these conditions are chronic, combining devices with different action mechanism or combing drug-device may allow better management of these diseases in the long term. However, more studies with long-term follow-up and randomized comparisons are required to establish its precise role and to understand the mechanisms of actions of each devices and methods.

\section{Conflicts of Interest}

The author has no financial conflicts of interest.

\section{REFERENCES}

1. Maradey-Romero C, Fass R. New and future drug development for gastroesophageal reflux disease. J Neurogastroenterol Motil 2014;20:6-16.

2. Chung H, Chon YE, Kim SU, et al. Noninvasive prediction of erosive esophagitis using a controlled attenuation parameter (CAP)-based risk estimation model. Dig Dis Sci 2016;61:507-516.

3. Kim KM, Cho YK, Bae SJ, et al. Prevalence of gastroesophageal reflux disease in Korea and associated health-care utilization: a national population-based study. J Gastroenterol Hepatol 2012;27:741-745.

4. El-Serag HB, Sweet S, Winchester CC, Dent J. Update on the epidemiology of gastro-oesophageal reflux disease: a systematic review. Gut 2014;63:871-880.

5. Lazarus B, Chen Y, Wilson FP, et al. Proton pump inhibitor use and the risk of chronic kidney disease. JAMA Intern Med 2016;176:238-246.

6. Abraham NS. Proton pump inhibitors: potential adverse effects. Curr Opin Gastroenterol 2012;28:615-620.

7. Yew KC, Chuah SK. Antireflux endoluminal therapies: past and present. Gastroenterol Res Pract 2013;2013:481417.

8. Du X, Hu Z, Yan C, Zhang C, Wang Z, Wu J. A meta-analysis of long follow-up outcomes of laparoscopic Nissen (total) versus Toupet (270 degrees ) fundoplication for gastro-esophageal reflux disease based on randomized controlled trials in adults. BMC Gastroenterol 2016;16:88.

9. Triadafilopoulos G. Stretta: a valuable endoscopic treatment modality for gastroesophageal reflux disease. World J Gastroenterol 2014;20:7730- 
7738 .

10. Arts J, Bisschops R, Blondeau K, et al. A double-blind sham-controlled study of the effect of radiofrequency energy on symptoms and distensibility of the gastro-esophageal junction in GERD. Am J Gastroenterol 2012;107:222-230.

11. DiBaise JK, Brand RE, Quigley EM. Endoluminal delivery of radiofrequency energy to the gastroesophageal junction in uncomplicated GERD: efficacy and potential mechanism of action. Am J Gastroenterol 2002;97:833-842.

12. Noar M, Squires P, Noar E, Lee M. Long-term maintenance effect of radiofrequency energy delivery for refractory GERD: a decade later. Surg Endosc 2014;28:2323-2333.

13. Auyang ED, Carter P, Rauth T, Fanelli RD; SAGES Guidelines Committee. SAGES clinical spotlight review: endoluminal treatments for gastroesophageal reflux disease (GERD). Surg Endosc 2013;27:2658-2672.

14. Higuchi K, Fujiwara Y, Okazaki H, et al. Feasibility, safety, and efficacy of the Stretta procedure in Japanese patients with gastroesophageal reflux disease: first report from Asia. J Gastroenterol 2007;42:205-210.

15. Herman RM, Wojtysiak D, Rys J, et al. Interstitial cells of Cajal (ICCs) and smooth muscle actin (SMA) activity after non-ablative radiofrequency energy application to the internal anal sphincter (IAS): an animal study [Internet]. Norwalk (CT): Mederi Therapeutics Inc.; c2013 [updated 2013; cited 2017 May 21]. Available from: https://www. secca-therapy.com/clinicals/interstitial-cells-of-cajal-iccs-and-smoothmuscle-actin-sma-activity-af.

16. Testoni PA, Mazzoleni G, Testoni SG. Transoral incisionless fundoplication for gastro-esophageal reflux disease: techniques and outcomes. World J Gastrointest Pharmacol Ther 2016;7:179-189.

17. Obesity: preventing and managing the global epidemic. Report of a WHO consultation. World Health Organ Tech Rep Ser 2000;894:i-xii, $1-253$.

18. OECD iLibrary. OECD health statistics [Internet]. Paris: OECD; c2015 [cited 2017 May 21]. Available from: http://dx.doi.org/10.1787/healthdata-en.

19. Hankey CR. Session 3 (Joint with the British dietetic association): management of obesity: weight-loss interventions in the treatment of obesity. Proc Nutr Soc 2010;69:34-38.

20. Sjöström L, Lindroos AK, Peltonen M, et al. Lifestyle, diabetes, and cardiovascular risk factors 10 years after bariatric surgery. N Engl J Med 2004;351:2683-2693.

21. Obeid NR, Malick W, Concors SJ, Fielding GA, Kurian MS, Ren-Fielding CJ. Long-term outcomes after Roux-en-Y gastric bypass: 10- to 13year data. Surg Obes Relat Dis 2016;12:11-20.

22. van Rijn S, Roebroek YG, Masclee AA, van Heurn EL, Bouvy ND. Structural endoscopic techniques to treat obesity: a review. Surg Technol Int 2015;26:84-91.

23. Abu Dayyeh BK, Edmundowicz S, Thompson CC. Clinical practice update: expert review on endoscopic bariatric therapies. Gastroenterology 2017;152:716-729.

24. Kumar N, Peña Sahdala HN, Shaikh S, et al. Endoscopic sleeve gastroplasty for primary therapy of obesity: initial human cases. Gastroenterology 2014;146(5 Suppl 1):S571-S572.

25. Abu Dayyeh BK, Acosta A, Camilleri M, et al. Endoscopic sleeve gastroplasty alters gastric physiology and induces loss of body weight in obese individuals. Clin Gastroenterol Hepatol 2017;15:37-43.el.

26. Abu Dayyeh BK, Rajan E, Gostout CJ. Endoscopic sleeve gastroplasty: a potential endoscopic alternative to surgical sleeve gastrectomy for treatment of obesity. Gastrointest Endosc 2013;78:530-535.

27. Sharaiha RZ, Kedia P, Kumta N, et al. Initial experience with endoscopic sleeve gastroplasty: technical success and reproducibility in the bariatric population. Endoscopy 2015;47:164-166.

28. Lopez-Nava G, Galvao M, Bautista-Castaño I, Fernandez-Corbelle JP, Trell M. Endoscopic sleeve gastroplasty with 1-year follow-up: factors predictive of success. Endosc Int Open 2016;4:E222-E227.

29. Lopez-Nava G, Sharaiha RZ, Neto MG, et al. Endoscopic sleeve gastroplasty for obesity: a multicenter study of 242 patients with 18 months follow-up. Gastroenterology 2016;150(4 Suppl 1):S26.

30. Kumar N, Lopez-Nava G, Peña Sahdala HN, et al. Endoscopic sleeve gastroplasty: multicenter weight loss results. Gastroenterology 2015;148(4 Suppl 1):S-179.

31. Gomez V, Woodman G, Abu Dayyeh BK. Delayed gastric emptying as a proposed mechanism of action during intragastric balloon therapy: results of a prospective study. Obesity (Silver Spring) 2016;24:1849-1853.

32. Mion F, Napoléon B, Roman S, et al. Effects of intragastric balloon on gastric emptying and plasma ghrelin levels in non-morbid obese patients. Obes Surg 2005;15:510-516.

33. Genco A, Bruni T, Doldi SB, et al. BioEnterics intragastric balloon: the Italian experience with 2,515 patients. Obes Surg 2005;15:1161-1164.

34. Farina MG, Baratta R, Nigro A, et al. Intragastric balloon in association with lifestyle and/or pharmacotherapy in the long-term management of obesity. Obes Surg 2012;22:565-571.

35. Sampath K, Rothstein RI. Selected endoscopic gastric devices for obesity. Gastrointest Endosc Clin N Am 2017;27:267-275.

36. Marinos G, Eliades C, Raman Muthusamy V, Greenway F. Weight loss and improved quality of life with a nonsurgical endoscopic treatment for obesity: clinical results from a 3- and 6-month study. Surg Obes Relat Dis 2014;10:929-934.

37. Schjoldager B, Mortensen PE, Myhre J, Christiansen J, Holst JJ. Oxyntomodulin from distal gut. Role in regulation of gastric and pancreatic functions. Dig Dis Sci 1989;34:1411-1419.

38. Tsoli M, Chronaiou A, Kehagias I, Kalfarentzos F, Alexandrides TK. Hormone changes and diabetes resolution after biliopancreatic diversion and laparoscopic sleeve gastrectomy: a comparative prospective study. Surg Obes Relat Dis 2013;9:667-677.

39. Yousseif A, Emmanuel J, Karra E, et al. Differential effects of laparoscopic sleeve gastrectomy and laparoscopic gastric bypass on appetite, circulating acyl-ghrelin, peptide YY3-36 and active GLP-1 levels in non-diabetic humans. Obes Surg 2014;24:241-252.

40. Jirapinyo P, Thompson CC. Endoscopic bariatric and metabolic therapies: surgical analogues and mechanisms of action. Clin Gastroenterol Hepatol 2017;15:619-630.

41. Fishman E, Melanson D, Lamport R, Levine A. A novel endoscopic delivery system for placement of a duodenal-jejunal implant for the treatment of obesity and type 2 diabetes. Conf Proc IEEE Eng Med Biol Soc 2008;2008:2501-2503.

42. Jain D, Singhal S. Endoscopic bypass using Endobarrier devices: efficacy in treating obesity and metabolic syndrome. J Clin Gastroenterol 2015;49:799-803.

43. Koehestanie P, Betzel B, Dogan K, et al. The feasibility of delivering a duodenal-jejunal bypass liner (EndoBarrier) endoscopically with patients under conscious sedation. Surg Endosc 2014;28:325-330.

44. Schouten R, Rijs CS, Bouvy ND, et al. A multicenter, randomized efficacy study of the EndoBarrier gastrointestinal liner for presurgical weight loss prior to bariatric surgery. Ann Surg 2010;251:236-243.

45. Rohde U. EndoBarrier gastrointestinal liner. Delineation of underlying mechanisms and clinical effects. Dan Med J 2016;63.

46. Rohde U, Hedbäck N, Gluud LL, Vilsbøll T, Knop FK. Effect of the EndoBarrier gastrointestinal liner on obesity and type 2 diabetes: a systematic review and meta-analysis. Diabetes Obes Metab 2016;18:300-305.

47. Patel SR, Mason J, Hakim N. The duodenal-jejunal bypass sleeve (EndoBarrier gastrointestinal liner) for weight loss and treatment of type II diabetes. Indian J Surg 2012;74:275-277.

48. Patel SR, Hakim D, Mason J, Hakim N. The duodenal-jejunal bypass sleeve (EndoBarrier gastrointestinal liner) for weight loss and treatment of type 2 diabetes. Surg Obes Relat Dis 2013;9:482-484.

49. ASGE Bariatric Endoscopy Task Force; ASGE Technology Committee, 
Abu Dayyeh BK, et al. Endoscopic bariatric therapies. Gastrointest Endosc 2015;81:1073-1086.

50. Bennett MC, Badillo R, Sullivan S. Endoscopic management. Gastroenterol Clin North Am 2016;45:673-688.

51. Cherrington AD, Rajagopalan H, Maggs D, Devière J. Hydrothermal duodenal mucosal resurfacing: role in the treatment of metabolic dis- ease. Gastrointest Endosc Clin N Am 2017;27:299-311.

52. Rajagopalan $\mathrm{H}$, Cherrington AD, Thompson CC, et al. Endoscopic duodenal mucosal resurfacing for the treatment of type 2 diabetes: 6-month interim analysis from the first-in-human proof-of-concept study. Diabetes Care 2016;39:2254-2261. 